\title{
In Their Own Words: Student Key Learning Experiences in an Introductory Evaluation Course
}

\author{
John M. LaVelle and Zhou Yang \\ University of Minnesota
}

\begin{abstract}
Reflections by students on their key learning experiences in evaluation courses can provide useful data for educators seeking to identify the most impactful aspects of their teaching practice. In this practice note we describe how an instructor has included active reflective practice as part of their teaching practice, and how both the instructor and a graduate student analyzed other student reflections on key learning experiences to help improve the course. We first analyze these reflections using grounded theory, then perform two additional analyses, one using Fink's taxonomy of significant learning and the second using both the Canadian Evaluation Society's Competencies for Canadian Evaluation Practice and the American Evaluation Association's Competencies framework. We conclude by reflecting on how the frameworks provided helpful data to understand and improve the practice of teaching evaluation through the lens of the student learner.
\end{abstract}

Keywords: course design evaluation, reflection, student learning, teaching of evaluation

Résumé : Les réflexions d'étudiantes et étudiants sur leurs principales expériences d'apprentissage dans des cours d'évaluation peuvent offrir des données utiles au sujet de l'impact de diverses approches d'enseignement. Dans cette note sur la pratique, nous décrivons une pratique réflexive active et la façon dont les réflexions d'autres étudiantes et étudiants sur leurs principales expériences d'apprentissage peuvent être analysées, en vue d'améliorer un cours. Nous avons tout d'abord analysé de telles réflexions en faisant appel à une théorie empirique, puis nous avons effectué deux analyses supplémentaires, l'une utilisant la taxonomie de Fink sur l'apprentissage significatif et la deuxième utilisant autant le cadre de la Société canadienne dévaluation (Référentiel des compétences professionnelles requises à l'exercice d'évaluation de programmes au Canada) que celui de l'American Evaluation Association (Competencies). Nous concluons en réfléchissant à la façon dont les cadres offrent des données utiles pour comprendre et améliorer la pratique de l'enseignement de l'évaluation et ce, du point de vue de l'étudiante et de l'étudiant.

Mots clés : évaluation du design d'un cours, réflexion, apprentissage étudiant, enseignement de l'évaluation

Corresponding author: John LaVelle, Department of Organizational Leadership, Policy, and Development, College of Education and Human Development, 323 Burton Hall, 178 Pillsbury Drive SE, Minneapolis, MN, 55455; jlavelle@umn.edu 
Evaluator education, a sub-field within evaluation research, focuses on where, how, and why evaluators are educated and socialized into the profession (Gullickson et al., 2019). King and Ayoo (2020) suggest ten major domains within evaluator education that researchers and scholars might investigate, including university-based systems (LaVelle, 2019; LaVelle \& Donaldson, 2010), pedagogies for the teaching of evaluation (LaVelle et al., 2020), the importance of practical learning experiences (Trevisan, 2004), and the needs of learners from different disciplines (Christie et al., 2014). Much of the recent literature, however, focuses on evaluator education systems and the educators themselves, with comparatively little attention on student learning or the ways in which data on this learning can be used in course design/redesign (King \& Ayoo, 2020). In response to this gap, we describe how we use students' reflections on key learning experiences in evaluation courses as data with which to examine our teaching practice.

\section{RETROSPECTIVE AND PROSPECTIVE REFLECTION}

Dewey (1933, p. 9) described reflection as an "active, persistent, and careful consideration of any form of belief or knowledge . . . and the grounds that support it and its conclusions." Shulman and Colbert (1989) later described reflective practice as the process of thinking backwards in time to analyze past events and behaviours and their consequences. Many evaluator educators and evaluation practitioners advocate for active reflective practice (King \& Stevahn, 2014), and reflection is highlighted as a critical aspect of practice for both Canadian and American evaluators (AEA, 2018; CES, 2018). Reflection is important for highquality evaluation practice, allowing evaluators to learn both from successes and from challenges that may have led to mistakes. Examples of retrospective reflections have been compiled into the book Evaluation Failures (Hutchinson, 2019), a gathering of stories and reflections to help evaluators process the successes and challenges in a completed evaluation.

Conway (2001) argued that reflective learning focused exclusively on past events is limited in its utility unless the reflector actively builds a cognitive link to future experiences and behaviour. He called this focus on the past a temporal truncation that can be addressed through anticipatory or prospective reflection (van Manen, 1995). In his phenomenological study on the preparation of teachers and their anticipated/real experiences in the classroom, Conway illustrated the utility of using prospective and retrospective reflections in tandem to understand the processes and meaning making of teachers' professional practice. He concluded that prospective reflection could assist with transitioning into a new work culture, anticipating challenges, and reinforcing learning. Similar lessons may be learned in evaluator education, by asking students both to reflect on past course content and experiences and to anticipate how these reflections will help inform future attitudes, thoughts, and behaviours. 


\section{KEY LEARNING EXPERIENCES}

A "key learning experience" refers to an important learning event or process that was particularly impactful for the learner and is elicited through a reflective prompt. Boyd and Fales (1983) suggested that students' reflection on impactful experiences is a critical component of experiential learning and that an educator experienced in reflecting on reflection itself should help foster the students' reflective process. Indeed, because asking students to reflect on their key learning experience from a course can elicit discomfort as well as excitement (Boyd \& Fales, 1983), the reflective process should be structured to allow students to feel both positive and negative emotions without judgement. Resolving the emotional state with new perspective is what prompts the "aha" moment for the reflector, leading to the conscious realization that their perspective has shifted. Timoštšuk and Ugaste (2012) later concluded that both positive and negative key learning experiences play an important role in the development of the professional identity of teachers; it is likely that the same is true for evaluators.

\section{FRAMING STUDENT REFLECTIONS}

Research on student reflections from classroom experiences varies greatly from field to field, and, depending on the discipline, the content of these reflections can range from the philosophical to the immediately practical, which makes their organization and analysis a challenge. Though little is currently known about students' reflections from evaluation-specific courses, at least three frameworks exist to help organize the data, each providing distinct insights into what students found most memorable. First, a grounded theory process (e.g., Miles \& Huberman, 1994) lets us read the students' reflections and see what categories emerge organically. Second, Barnes and Caprino's 2016 illustration of Fink's (2003) taxonomy of learning outcomes offers a helpful framework for organizing students' reflections from a service-learning course; the data can be organized in terms of foundational knowledge, application, integration, human dimensions, caring (new values and perspectives about self or others), and learning how to learn (p. 565). Third, we can use a competency-based framework such as the CES Competencies for Canadian Evaluators (2018) or the AEA Competencies (2018). Illustrating different aspects of student learning, all three approaches have value for educators.

\section{PROCESS}

The Institutional Review Board at University of Minnesota-Twin Cities categorized this scholarship as "exempt" because the data were collected as part of the regular course assessment process. 


\section{Context and participants}

I-the first author-have taught the Introduction to Evaluation as a practicebased course for over ten years across three universities. My course has reached more than 400 graduate and 100 undergraduate students from a range of disciplinary backgrounds including psychology, organizational behavior and development, human resource development and education, K-12 and higher education, public health, public policy and administration, and business. I designed the course as a service-learning course that meets one evening per week (Furco, 1996; Furco \& Billig, 2001; LaVelle et al., 2020). I review and update my course materials every semester based on student feedback and performance, incorporating additional information from an ongoing scan of the evaluation job marketplace and from the students' reflections on their key learning experiences.

\section{Course content and student experiences}

The course topics and outline closely follow the main topics in Russ-Eft and Preskill's (2009) textbook Evaluation in Organizations. Topics include defining and describing evaluation, the logic of evaluation, evaluation theories of practice, evaluator roles, politics, stakeholder-driven logic models, outcome definitions, evaluation design and inquiry methodology, communication strategies, and budgeting. Students are required to engage in service learning to design and deliver a formal evaluation proposal for their community partner. The proposal elements undergo several rounds of public and private review, with students presenting the logic models, stakeholder-generated outcome descriptions contrasted with scholarly definitions, stakeholder-driven key evaluation questions, and the students' proposed design, data-collection tools, budget, and anticipated communication strategies.

\section{Prompts for reflection}

All students participating in my Introduction to Evaluation Practice course respond to three reflective questions on their take-home final exam. Because of the reflective nature of the questions, I distribute the exam the first night of class and refer students to it throughout the semester. The first question prompts students to develop a personal statement about evaluation and describe both the field and its processes using non-technical language. The second asks them to take a philosophical stance on evaluation's role in social justice, and the third prompts them to reflect for one page on their key learning experience from the course-specifically, on their most impactful learning and how it will influence their future behaviour and/or perspectives. This prompt is what generated the qualitative data analyzed in this practice note. The exam weighs $10 \%$ of the final grade and is an important component that fosters learning transfer. We analyzed all students' responses; no sampling was required. 


\section{DESCRIPTIONS OF STUDENT LEARNING}

The richness of the qualitative data called for multiple approaches to its analysis (Tashakkori \& Teddlie, 1998). As a team, we holistically analyzed the student course data at the paragraph level of analysis, using three processes. For each approach, we used a random sample of fifteen student responses (approximately $5 \%$ of the total responses) to familiarize ourselves with the framework and build intra-team consensus on how the students' words matched onto the themes. First, we used a grounded theory/taxonomy-free inductive approach wherein we read the reflections and compiled a list of major themes. After discussing the themes iteratively to build inter-rater agreement and to reduce their number, we arrived at three major groups: personal development, professional development, and career development. We next used a deductive approach based on Fink's (2003) taxonomy of significant learning outcomes, and then on the broad categories offered by the CES Competencies for Canadian Evaluators (2018) and the AEA Competencies (2018).

Table 1 illustrates the results of the grounded theory-free inductive analysis. Several broad categories emerged; while these are presented orthogonally, many of the student reflections intersected to include personal, professional, and careerdevelopment topics. We differentiated "professional development" from "career development" because the constructs exist on two different conceptual levels; in general, professional development has a more immediate focus on technical and interpersonal skills, while career development focuses on a future career trajectory supported by a person's interests, skills, and abilities (Chaplowe \& Cousins, 2016).

Table 2 presents the student reflections categorized by Fink's (2003) taxonomy of significant learning outcomes. Because it forces them into predetermined categories, this taxonomy broadly organizes the reflections into a structure more amenable to course design/redesign. Student responses suggested that most key learning experiences were linked with the application of evaluation principles and concepts to practice; remaining ones were linked with foundational knowledge of the field and with its humanistic/interpersonal dimensions. Less emphasis was placed on caring or on learning how to learn.

The third step we took was to compare the student key learning experience narratives with the available North American Evaluator Competency frameworks. We began with the broad domains of the AEA competencies (2018) because the authors are located in the United States, and then used the CES competency domains (2018) (see Table 3). Though the student narratives broadly aligned with many of the competencies, readers should interpret this crosswalk cautiously because students were asked to reflect on their most impactful learning moment, not to describe their understanding of every aspect of evaluation practice after a single course experience. We found it interesting, however, that many of the reflections aligned with the interpersonal/humanistic aspects of the competencies, and comparatively fewer discussed the more technical aspects of evaluation work. 


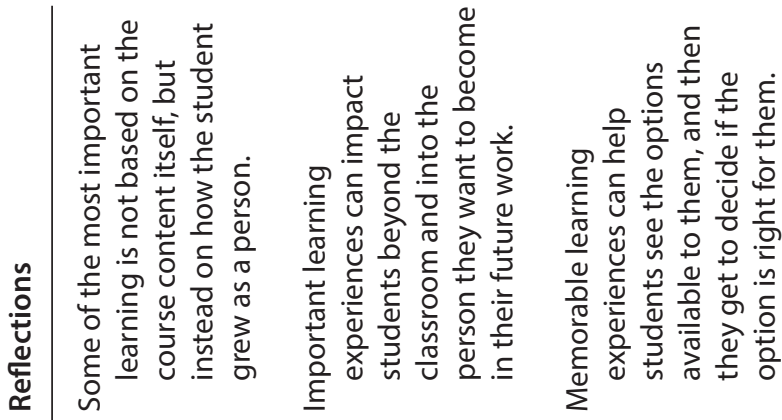

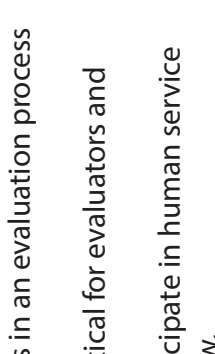

غ்ุ

$\stackrel{0}{\circ}$

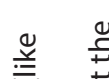

孚

흥

일 है

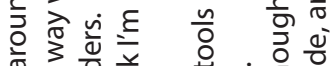

婇 응

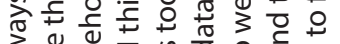

उั

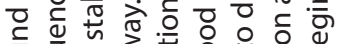

는

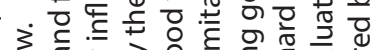

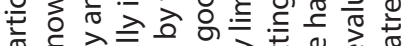

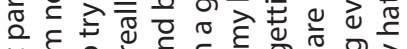

응 흐늠

\&讨

宅 产高

एँ

응

$\varepsilon$ \&

$\frac{1}{8} \frac{d}{d}$

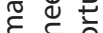

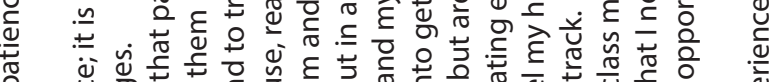

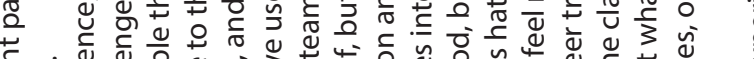

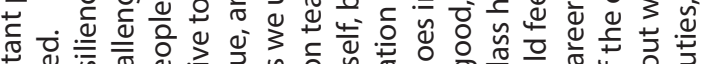

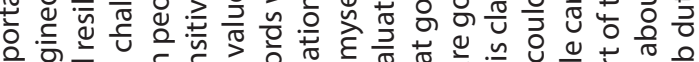

ह

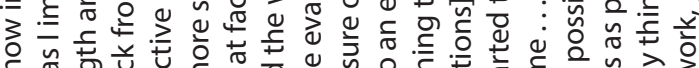
ᄃ

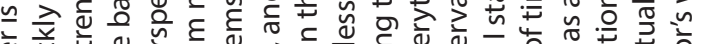

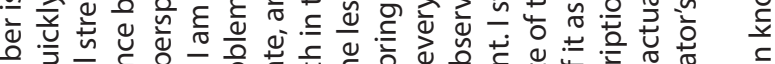

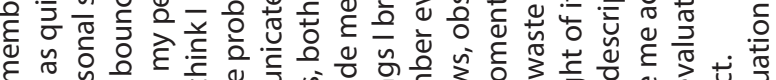
ब

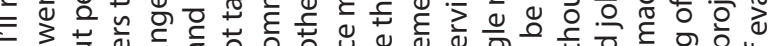
б

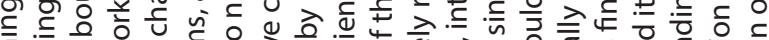

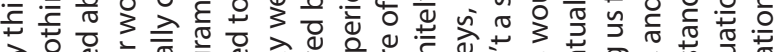

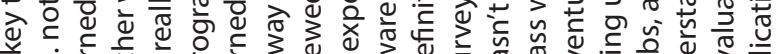
永 


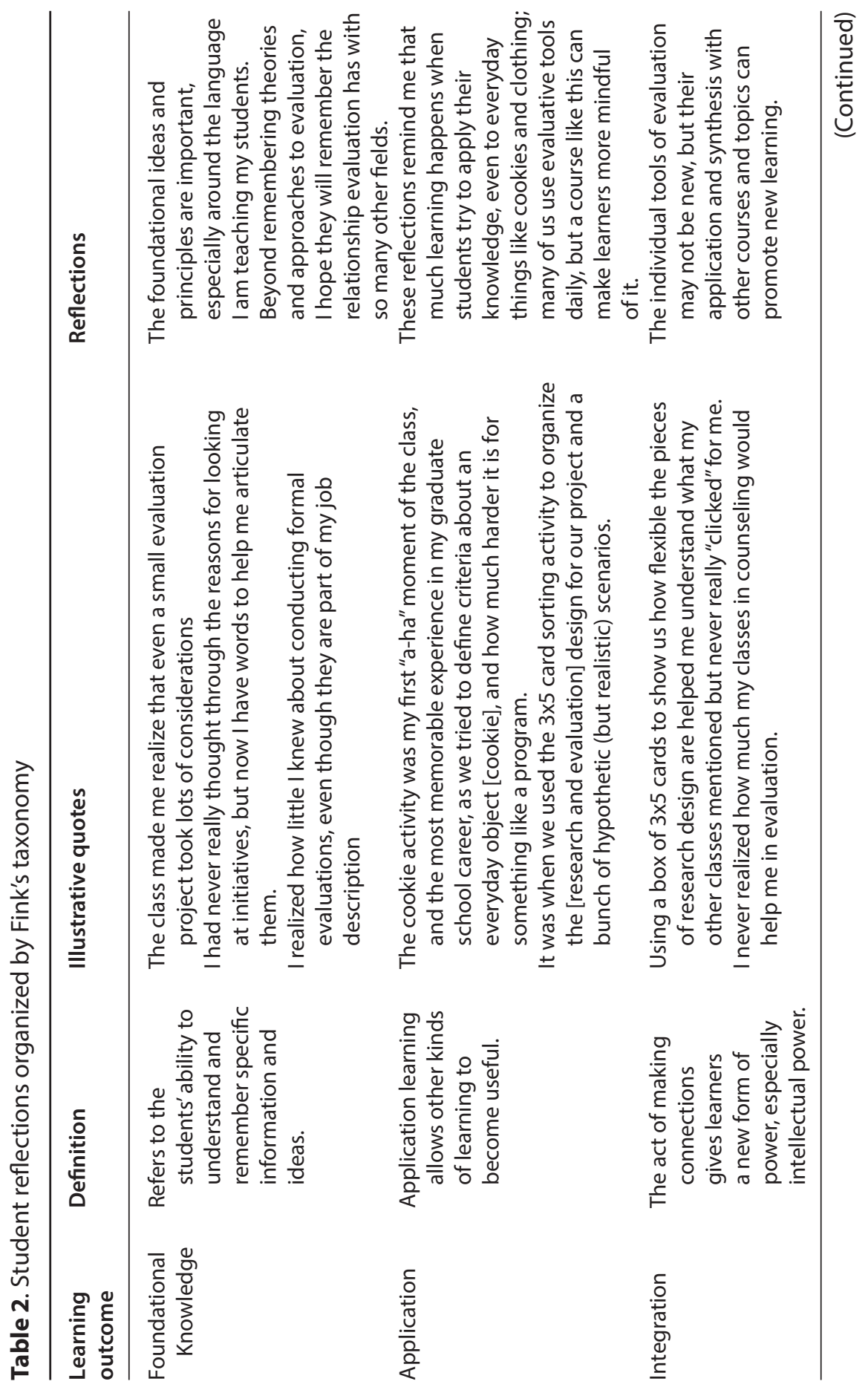




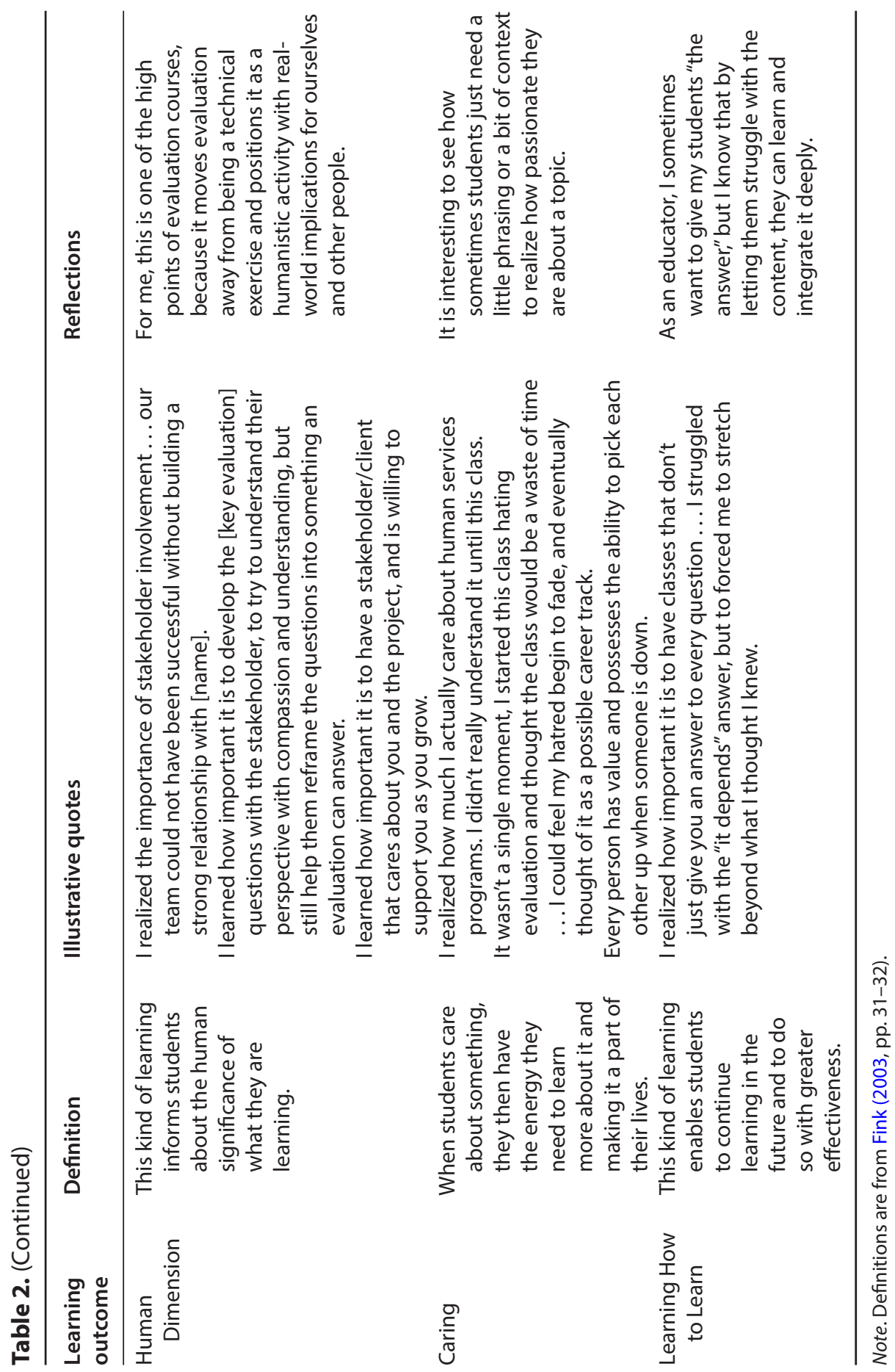




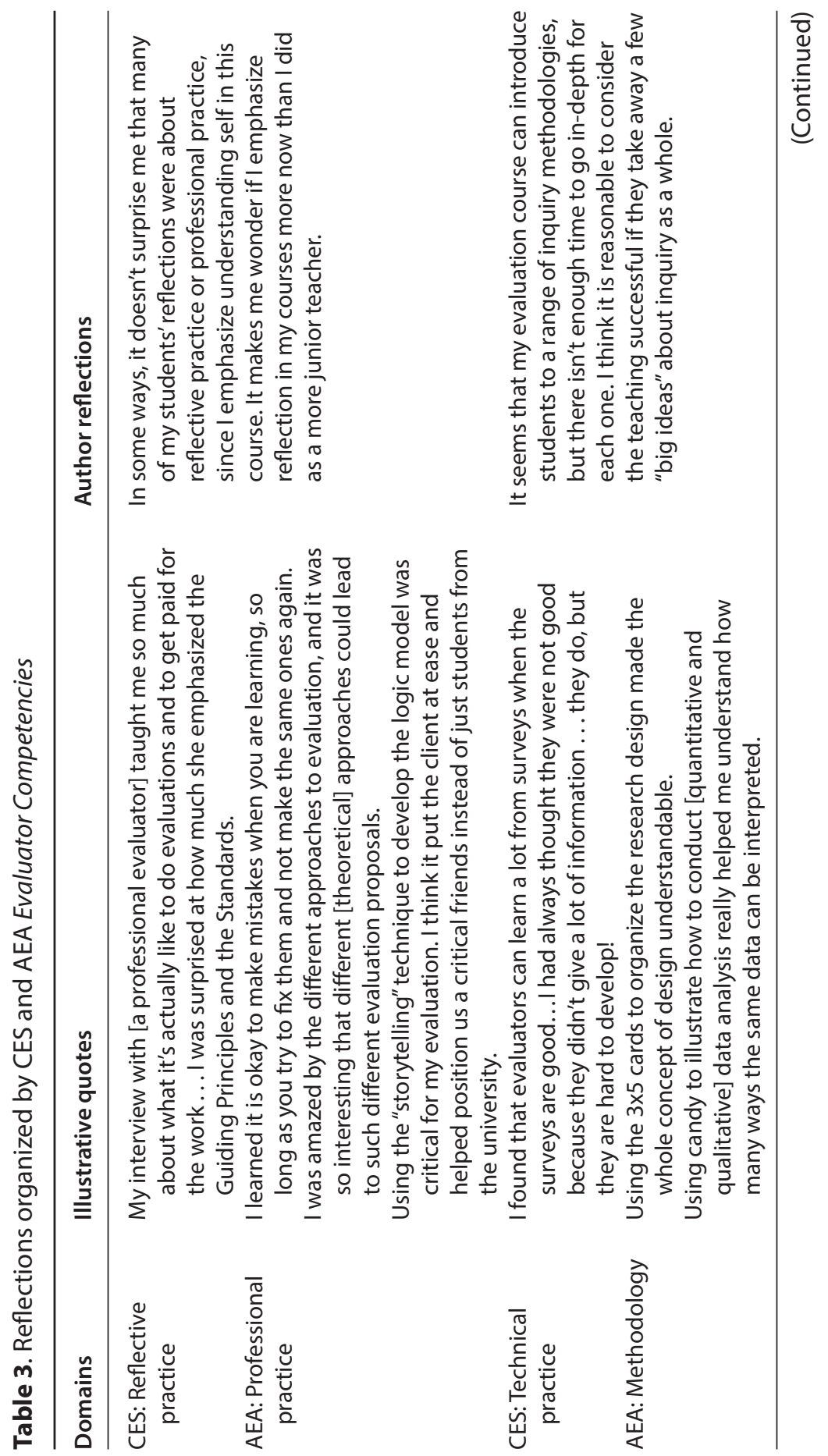




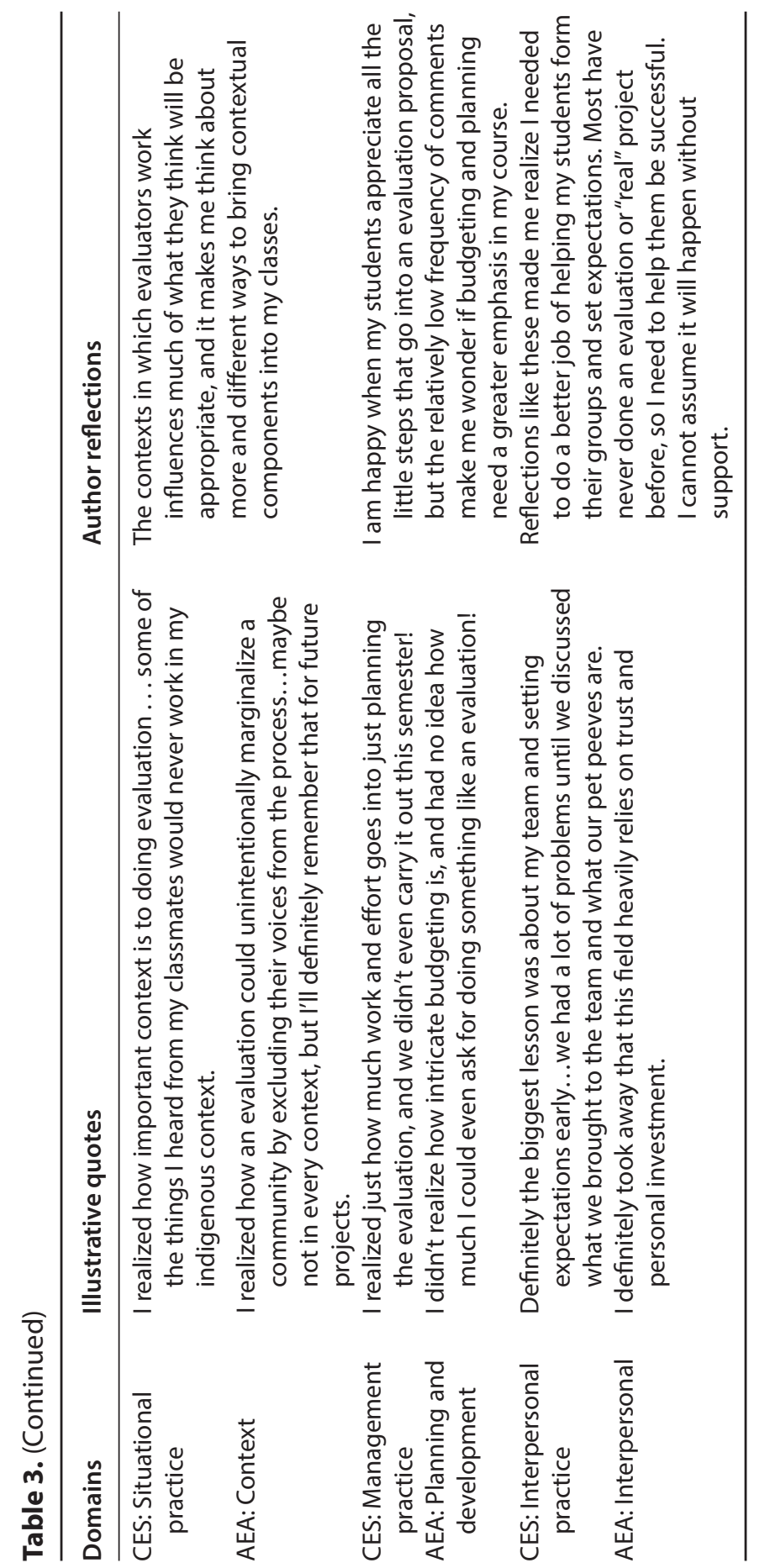




\section{TEACHER REFLECTION}

I find teaching evaluation exhilarating and take great joy in helping students learn while also providing conceptual-and sometimes operational-support for community partners that work and serve communities near the university. Like most program stakeholders, I also experience a bit of the usual evaluation anxiety when it comes time to examine my own teaching practice (Donaldson et al., 2002), though I take a formative lens on the practice. Indeed, reflection on my teaching of evaluation is as critical to my development as an educator as reflective evaluation practice is to the practicing evaluator.

After the semester is complete and I have submitted final grades to the Registrar, I closely review my syllabus, teaching materials, and teaching activities. I then review the student key learning experience data and reflect on the purpose of the course itself. With this introductory program evaluation course, my aim is to give students an introduction to the field and its foundational documents (e.g., the AEA Guiding Principles, Standards, Statement on Cultural Competence, Competencies etc.), and help them contrast several theoretical approaches to evaluation practice. I also want them to develop evaluation and inquiry skills while they provide conceptual support to a community partner. And I have the implicit goal-not a learning objective-of the course experience helping to humanize the students, the course content, and the community partners (LaVelle, 2020). In sum, my course is meant to develop critical consumers of evaluation and increase students' familiarity with the field, not necessarily to create stand-alone professional practitioners (Morris, 1994); I believe that would require several courses in evaluation that are explicitly supported by inquiry methods and data analysis.

With these goals in mind, I review the student reflections and the syllabus side-by-side, looking for broad alignment between the reflections and the major topics outlined in the syllabus and teaching materials. I assume that when specific teaching activities are described several times as impactful, they were mainly effective for this group of students. For example, students often point to our use of chocolate chip cookies to illustrate evaluation logic as their key learning experience (Preskill \& Russ-Eft, 2016), so I maintain both the activity and its current framing without much change. As well, students often reflect on the activities that address cultural assumptions, research design, and the development of program logic models through role-playing, so I will maintain these activities in the future as well. Not all of my activities, however, make it into the reflective papers, which I take as an indication that I should re-examine both the activity and the topic I was trying to address. Lack of discussion doesn't necessarily mean that the activity was bad or implemented poorly, though that could certainly be the case; it could simply mean that other learning experiences were more impactful for this group of students.

The process of writing this paper has helped me think further about the goals and outcomes of an evaluation-specific course, how to solicit reflections (Boyd \& Fales, 1983), and how to organize these reflections so I can understand where and how the course worked for the students and where I should make 
adjustments. The inductive approach to analyzing student reflections helped me see where my students were both professionally and personally, but it lacked the structure to provide insights on how to improve my teaching practice. Similarly, the CES (2018) and the AEA (2018) Competencies frameworks were too detailed to be helpful; they left me with a sense of having failed my students because of the impossibility of addressing each competency in depth in a single course (Tucker, personal communication, 2018). They might be more appropriate for analyzing a series of workshops or an entire curriculum than a single course. Framed another way, this experience taught me that educators must be selective about which competencies are targeted in a single course.

By contrast, Fink's (2003) taxonomy of significant learning outcomes was immensely helpful in organizing the students' reflections into broad clusters that I use to understand my teaching practice. Most memorable for me were the student reflections about what it meant to be a good teammate, the students who said the course helped them think differently about people who participate in programs, or the ones who realized they had a passion for helping specific groups of people. These "humanistic" reflections have influenced how I approach my courses and how I encourage students to consider the programs they are proposing to evaluate (LaVelle, 2020), as well as which aspects of evaluation practice I emphasize in my class.

Ultimately, the students' reflections on their key learning experiences have proven to be a rich source of ideas and inspiration, allowing me to take a critical look at my teaching practice and seek continuous improvement. They have also given me an opportunity to ask my students how my class and my teaching have made an impact in their lives and perspectives. As a teacher, evidence of influence within and beyond the classroom is the greatest reward I could hope for.

\section{STUDENT REFLECTION}

The process of analyzing student reflections was an interesting experience, and I-the second author-saw that my peers took different learnings from the class even though we had similar in-class experiences. Using the different frameworks helped me see how frequently used words and ideas could mean very different things based on how they were communicated, contextualized, and analyzed.

First, I found that reflections on key learning experiences can be used as a tool to identify students' intended and unintended learning outcomes. As a student, I assume that many professors design their courses with the intention that they be useful for students later on, but the connection between what is taught and what is memorable is not always clear to either professor or student. In these reflections, many students started by describing their "aha" moments, then explaining how what they learned can be applied to their future evaluation practice or work. Others described drawing connections between their experiences and their perception of future professional behaviours - connections that can be applied across contextsor learning that they have a passion (or not) for community-engaged work. 
This experience has made me more aware of the importance of the language used by professors and others to introduce new ideas and reinforce important concepts. The students' key learnings came from many sources, including class activities, lectures, group meetings, and meetings with clients, meaning that educators must be consistent in their use of words and examples as they introduce and reinforce central ideas. I also started to look at the jargon that people learn in the classroom, and realized that a person can be very professional and respected even when using non-technical language. As I look back at the course description and other documents, I realize how much attention was paid to making the content serious but accessible.

I found the reflections an interesting source of ideas for making changes to the course design and teaching strategies, and think that the prompt encouraged students to be honest about their most important experience because there were no "wrong" answers. Some students introduced their "aha" moment by describing a specific challenge or difficulty they encountered and indicating "I wish I had ..." or "I should have ...." Professors can use these reflections to understand where students struggled and address these difficulties the next time the course is taught. These reflections can also prompt a teacher to consider what they would do in a similar situation and what they would advise the student to do differently next time.

The reflection seems an important chance for students to relearn or solidify their understanding of the course material, as they revisit that material and reflect on what worked and didn't. Some students share that evaluation theories and models look easy when we discuss them in class, but are difficult to apply in practice. This kind of reflection could be an important aspect of many courses, both inside and outside of evaluation, because it moves the focus of the learning away from a test or project to something more substantial: how to identify individual strengths and limitations, and to overcome challenges.

Finally, this experience reinforced to me the importance of process-based as well as content-based courses for both evaluation majors and non-majors. The majority of students who wrote these reflections were not evaluation majors, but were from fields such as social work, natural sciences, human resources, and public health. Many shared in the reflection assignment that the course not only helped them gain knowledge about evaluation, but helped prepare them for consulting positions, entrepreneurship, or work in an organization. They may not remember some of the specific content, but they can look that up later; what I think they will remember is the experience of designing an evaluation proposal for the first time and the explicit linking of an intensive course with valued and marketable skills.

\section{CONCLUSION}

In this paper we have introduced active reflections as part of course design, analyzed how students' reflections on their key learning experiences help improve a 
course, and how reflection assignments build up students' interpersonal skills, professional competencies, and career readiness. Both the instructor and student found students' reflections to be an effective method for maximizing learning outcomes, an efficient approach to summarizing successful experiences, and a chance to learn what can be done better and how to make improvements. We hope other educators will follow this process. The costs are low, and the rewards great.

\section{REFERENCES}

American Evaluation Association (AEA). (2018). AEA evaluator competencies. https:// www.eval.org/page/competencies

Barnes, M. E., \& Caprino, K. (2016). Analysing service-learning reflections through Fink's taxonomy. Teaching in Higher Education, 21(5), 557-575. https://doi.org/10.1080/13 562517.2016.1160221

Boyd, E. M., \& Fales, A. W. (1983). Reflective learning: Key to learning from experience. Journal of Humanistic Psychology, 23(2), 99-117. https://doi.org/10.1177/0022167883 232011

Canadian Evaluation Society (CES). (2018). Competencies for Canadian evaluators. https:// evaluationcanada.ca/competencies-canadian-evaluators

Chaplowe, S. G., \& Cousins, J. B. (2016). Monitoring and evaluation training: A systematic approach. Sage.

Christie, C. A., Quiñones, P., \& Fierro, L. (2014). Informing the discussion on evaluator training: A look at evaluators' course taking and professional practice. American Journal of Evaluation, 35(2), 274-290. https://doi.org/10.1177/1098214013503697

Conway, P. F. (2001). Anticipatory reflection while learning to teach: From a temporally truncated to a temporally distributed model of reflection in teacher education. Teaching and Teacher Education, 17, 89-106. https://doi.org/10.1016/s0742-051x(00)00040-8

Dewey, J. (1933). How we think: A restatement of the relation of reflective thinking to the educative process. Houghton Mifflin.

Donaldson, S. I., Gooler, L. E., \& Scriven, M. (2002). Strategies for managing evaluation anxiety: Toward a psychology of program evaluation. American Journal of Evaluation, 23(3), 261-273. https://doi.org/10.1177/109821400202300303

Fink, L. D. (2003.) Creating significant learning outcomes: An integrated approach to designing college courses. Jossey-Bass.

Furco, A. (1996). Service-learning: a balanced approach to experiential education. In B. Taylor \& Corporation for National Service (Eds.), Expanding boundaries: Serving and learning (pp. 2-6). Corporation for National Service.

Furco, A., \& Billig, S. (2001). Service learning: Essence of the pedagogy. Information Age Publishing.

Gullickson, A. M., King, J. A., LaVelle, J. M., \& Clinton, J. M. (2019). The current state of evaluator education: A situation analysis and call to action. Evaluation and Program Planning, 75, 20-30. https://doi.org/10.1016/j.evalprogplan.2019.02.012

Hutchinson, K. (2019). Evaluation failures: 22 tales of mistakes made and lessons learned. Sage. 
King, J. A., \& Ayoo, S. (2020). What do we know about evaluator education? A review of peer-reviewed publications (1978-2018). Evaluation and Program Planning, 79, 101785. https://doi.org/10.1016/j.evalprogplan.2020.101785

King, J. A., \& Stevahn, L. (2014). Interactive evaluation practice: Mastering the interpersonal dynamics of program evaluation. Sage.

LaVelle, J. M. (2019). Educating evaluators 1976-2017: An expanded analysis of university-based evaluation education programs. American Journal of Evaluation, 41(4), 494-509. https://doi.org/10.1177/1098214019860914

LaVelle, J. M. (2020). Using a program evaluation course to foster service and humanize students, faculty, and community partners. In E. Sengupta, P. Blessinger, \& M. Makhanya (Eds.), International perspectives on integrating community service into the curriculum: Humanizing higher education. Innovations in Higher Education Teaching and Learning (vol. 25, pp. 129-146). Emerald Group Publishing.

LaVelle, J. M., \& Donaldson, S. I. (2010). University-based evaluation training programs 1980-2008: An empirical review. American Journal of Evaluation, 31(1), 9-23.

LaVelle, J. M., Lovato, C., \& Stephenson, C. L. (2020). Towards a pedagogy for the teaching of evaluation. Evaluation and Program Planning, 79, 101786. https://doi.org/10.1016/j. evalprogplan.2020.101786

Miles, M. B., \& Huberman, A. M. (1994). Qualitative data analysis: An expanded sourcebook. Sage.

Morris, M. (1994). The role of single evaluation courses in evaluation training. In J. W. Altschuld \& M. Engle (Eds.), The preparation of professional evaluators: Issues, perspectives, and programs. New Directions for Program Evaluation, 62 (pp. 51-60). Jossey-Bass.

Preskill, H., \& Russ-Eft, D. (2016). Building evaluation capacity: Activities for teaching and learning (2nd ed.). Sage.

Russ-Eft, D., \& Preskill, H. (2009). Evaluation in organizations: A systematic approach to enhancing learning, performance, and change (2nd ed). Basic Books.

Shulman, J. H., \& Colbert, J. A. (1989). Cases as catalysts for cases: Inducing reflection in teacher education. Action in Teacher Education, 11(1), 44-52. https://doi.org/10.1080/ 01626620.1989 .10462714

Tashakkori, A., \& Teddlie, C. (1998). Mixed methodology: Combining qualitative and quantitative approaches (vol. 46). Sage.

Timoštšuk, I., \& Ugaste, A. (2012). The role of emotions in student teachers' professional identity. European Journal of Teacher Education, 35(4), 421-433. https://doi.org/10.1 080/02619768.2012.662637

Trevisan, M. S. (2004). Practical training in evaluation: A review of the literature. American Journal of Evaluation, 25(2), 255-272. https://doi.org/10.1177/109821400402500212

van Manen, M. (1995). On the epistemology of reflective practice. Teachers and Teaching: Theory and Practice, 1(1), 33-50. https://doi.org/10.1080/1354060950010104

\section{AUTHOR INFORMATION}

John LaVelle is an assistant professor in evaluation studies at the University of Minnesota. His research examines how universities prepare evaluators for applied work, and he has 
written on the intersection of job markets and university programs, techniques for recruiting evaluators, evaluator competencies, the psychology of evaluators, and how evaluators can use social science theory to inform their practice. He was awarded the American Evaluation Association's Marcia Guttentag Award in 2019.

Zhou Yang is a doctoral student in human resources development at the University of Minnesota. She received her M.Ed in human resources development in 2016. Her research interest resides at the intersection of organizational theory, strategy, and evaluation, with a focus on understanding how talent development programs shape and guide behaviours in organizations, and how it affects individual and firm performance. 